\title{
Prevalence of gynecological diseases in postmenopausal women in tertiary care hospital in Chengalpattu district
}

\author{
S. Shwetha*, S. N. S. Minnalkodi, Geetha Prasad
}

\begin{abstract}
Department of Obstetrics and Gynecology, Karpaga Vinayaga Institute of Medical Sciences and Research Centre,
\end{abstract} Chinna Kolambakkam, Tamil Nadu, India

Received: 24 June 2020

Revised: 25 July 2020

Accepted: 29 July 2020

\author{
*Correspondence: \\ Dr. S. Shwetha, \\ E-mail: selvashwe7@gmail.com
}

Copyright: (c) the author(s), publisher and licensee Medip Academy. This is an open-access article distributed under the terms of the Creative Commons Attribution Non-Commercial License, which permits unrestricted non-commercial use, distribution, and reproduction in any medium, provided the original work is properly cited.

\begin{abstract}
Background: Menopause is a biological event characterized by the complexity of factors. On an average one-third of the women's life consists of the post-menopause years, and health care programs for women do not address concerns beyond reproductive ages. The aim of this study was to describe the magnitude of menopause-related symptoms, the pattern of health care seeking, and associated factors. To assess the prevalence of gynecological disease in postmenopausal women.

Methods: This cross-sectional study was done in Karpaga Vinayaga Institute of Medical Sciences and Research Center - obstetrics and gynecology OPD. Over a period, months in the year 2019. Stages of reproductive aging workshop (STRAW) revised criteria and nomenclature are used for the ascertainment of menopause and inclusion of the women in the study. It provided a comprehensive basis for staging since there were more complexities on ascertainment of menopause explained. The STRAW criteria are considered as the gold standard for assessing menopausal stages.

Results: A total of 600 participants were included in the study. The proportion of women who had at least one menopause-related symptom was 95.95 (95\% CI 93.73-97.54) and 58.3\% of women had severe symptoms. Severities of symptoms in psychological, physical, vasomotor, and sexual domains were $56.7 \%, 70.5 \%, 49.3 \%$, and $10.2 \%$ respectively. Premature menopause $(\mathrm{p}<0.016)$, induced nature of menopause $(\mathrm{p}<0.031)$, dyslipidemia $(\mathrm{p}<0.006)$ and other medical condition $(\mathrm{p}<0.003)$ were associated with severity of menopausal related symptoms.

Conclusions: A high proportion of women are affected by menopause-related symptoms. Care seeking for all symptoms is not uniform, indicative of a lack of knowledge about the treatable nature of many of these symptoms. Sensitization of both women and the health care system may serve to address this issue of menopause-related symptoms and the possibility of treatment for these.
\end{abstract}

Keywords: Cardiovascular disease, Diabetes mellitus, Final menstrual period, Green climacteric scale

\section{INTRODUCTION}

Menopause is considered to be a marker of biological aging in women (WHO technical Group, 1996). Menopause is one of the most significant stages in the female reproductive life cycle where there is a transition from reproductive to the nonreproductive stage. This brings in several physiological changes that affect the life of a woman permanently. It sets the stage for aging and accelerates the process of non-communicable disorders. ${ }^{1,2}$ The complexity of various factors such as hormonal, psychological, social, cultural, and aging factors produces a difference in symptoms and long-term health outcomes. ${ }^{3}$ The hormonal and behavioural changes that 
occur during the menopausal period lead to a high demand for special health care. Menopause introduces a major change in the morbidity pattern in the middle life of the woman. ${ }^{4}$ The proportion of women who experience premature menopause either due to biological or otherwise induced reasons has a long duration of exposure to menopause leading to severe symptoms when compared to women who have undergone menopause naturally. ${ }^{5}$ Perimenopausal women reported more psychosomatic symptoms than pre- or postmenopausal women. ${ }^{6}$ Cultural factors influencing women's physical and psychological health varied across societies. Attitudes towards menopause may be related to different cultural practices and it also depends on the social construction of menopause. ${ }^{7,8}$

\section{METHODS}

This cross-sectional study was done in Karpaga Vinayaga Institute of Medical Sciences and Research Center obstetrics and gynecology OPD. Over a period, months in the year 2019. Stages of reproductive aging workshop (STRAW) revised criteria and nomenclature are used for the ascertainment of menopause and inclusion of the women in the study. It provided a comprehensive basis for staging since there were more complexities on ascertainment of menopause explained. The STRAW criteria are considered as the gold standard for assessing menopausal stages. At the center of the selected wards, the main junction was located and by using the pen rotating method, the first household of the randomly selected road was approached for data collection.

\section{Inclusion criteria}

Inclusion criteria of this study were; the women in the age group 35-60 years old who was in menopausal transition or postmenopausal phase and/or attained menopause either naturally or induced were included in the study.

\section{Exclusion criteria}

Exclusion criteria of this study were; women who were pregnant or lactating or had recent abortion (within 3 months) or critically ill or currently receiving hormone therapy or oral contraceptives were excluded from the study. Women who were not willing to give consent also excluded from the study.

STRAW revised criteria and nomenclature are used for the ascertainment of menopause and inclusion of the women in the study. It provided a comprehensive basis for staging since there were more complexities on ascertainment of menopause explained. The STRAW criteria are considered as the gold standard for assessing menopausal stages. Data collection was done using a structured questionnaire and the adapted green climacteric scale to assess menopause-related symptoms.

\section{Statistical analysis}

The data was entered in Epi data and analyzed by IBM SPSS version 21 software. The data has been presented using descriptive statistics for the prevalence of menopause-related symptoms, health-seeking behavior, and other variables. Bivariate analyses have been done to examine the relationship between predictor and outcome variables.

\section{RESULTS}

Table 1: Profile of the participants by healthrelated characteristics.

\begin{tabular}{|c|c|}
\hline Variables & $\begin{array}{l}N=600 \\
(100 \%)\end{array}$ \\
\hline \multicolumn{2}{|l|}{ Physical activity } \\
\hline Sedentary & $34(8.1 \%)$ \\
\hline Mild Physical activity & $183(43.6 \%)$ \\
\hline Moderate & $184(43.8 \%)$ \\
\hline Severe physical activity & $19(4.5 \%)$ \\
\hline \multicolumn{2}{|l|}{ Dietary choice } \\
\hline Vegetarian & $28(6.7 \%)$ \\
\hline Nonvegetarian & $392(93.3 \%)$ \\
\hline \multicolumn{2}{|l|}{ Diet control } \\
\hline Have control in consuming fat and sugar & $169(40.2 \%)$ \\
\hline Do not have control of fat and sugar & $233(55.5 \%)$ \\
\hline Have control over fat or sugar in the diet & $18(4.3 \%)$ \\
\hline \multicolumn{2}{|l|}{ Previous menstrual irregularity } \\
\hline Have menstrual irregularity & $63(15 \%)$ \\
\hline Did not have menstrual irregularity & $357(85 \%)$ \\
\hline \multicolumn{2}{|l|}{ Number of pregnancies } \\
\hline No pregnancy yet & $18(4.3 \%)$ \\
\hline One & $46(11 \%)$ \\
\hline Two & $234(55.7 \%)$ \\
\hline Three & $91(21.7 \%)$ \\
\hline Four and more & $31(7.3 \%)$ \\
\hline \multicolumn{2}{|l|}{ Number of deliveries } \\
\hline One & $42(10 \%)$ \\
\hline Two & $245(58.3 \%)$ \\
\hline Three & $83(19.8 \%)$ \\
\hline Four and more & $32(7.6 \%)$ \\
\hline Not applicable & $18(4.3 \%)$ \\
\hline \multicolumn{2}{|l|}{ Normal vaginal delivery } \\
\hline One & $50(11.9 \%)$ \\
\hline Two & $186(44.3 \%)$ \\
\hline Three & $70(16.7 \%)$ \\
\hline Four & $26(6.2 \%)$ \\
\hline Five and more & $3(0.7 \%)$ \\
\hline Not applicable & $85(20.2 \%)$ \\
\hline \multicolumn{2}{|l|}{ Caesarean section delivery } \\
\hline One & $48(11.4 \%)$ \\
\hline Two & $57(13.6 \%)$ \\
\hline Three & $2(0.5 \%)$ \\
\hline Not applicable & $313(74.5 \%)$ \\
\hline \multicolumn{2}{|l|}{ Complication during delivery } \\
\hline Had any complication & $39(9.3 \%)$ \\
\hline Did not had any complication & $365(86.9 \%)$ \\
\hline
\end{tabular}


In Table 1, nearly half of the women had either mild to sedentary in terms of physical activity (51.7\%). Quite a significant number of women reported a moderate level of physical activity $(43.8 \%)$. Almost all were nonvegetarians $(93.3 \%)$ and close to three-fifths of them had no control over either sugar or fat or both in their diet.

Only $15 \%$ of the women experienced menstrual irregularities. Fertility was near-universal; just less than five percent $(4.3 \%)$ were nulliparous. The majority of the women had one or two children $(66.7 \%)$. One out of four women in the study had undergone at least one c-section if not two. Close to 10 percent of the women (9.3\%) had experienced some form of complication (other than that requiring c-section) during delivery. Nearly one out of 20 women in the study had experienced gynecological morbidity $(18.9 \%)$. There was nearly 1.4 percent with some form of gynecological cancers, including breast cancer, ovarian cancer, and cervical cancer. The prevalence of self-reported high blood pressure, type 2 diabetes mellitus, and high cholesterol in the sample population was $38.8 \%, 26.7 \%$, and $35 \%$ respectively. There were $14.5 \%$ of women with other medical conditions in the study. The presence of central obesity measured by waist circumference indicates that around $46 \%$ of the women in the study had a waist circumference of more than $80 \mathrm{~cm}$.

In Table 2 a total 80 participants had a history of diagnosis of gynecological morbidity. Treatment seeking for these and other health conditions is described in table 4.3. Around $52 \%$ of them sought treatment in private secondary or tertiary hospitals. One woman who had a condition of gynecological morbidity sought care both in public and a private health care facility. There were 268 participants among 600 who were reported to have at least one of the chronic medical conditions such as hypertension, diabetes mellitus, high cholesterol, or other medical conditions including cancers. Among the 268 women, $32.1 \%$ sought care in private clinics, and $22.4 \%$ sought care in public primary health centers.

Table 2: Clinical profile of patients related to comorbid conditions.

\begin{tabular}{|ll|}
\hline Variable & $\begin{array}{l}\mathbf{N}=\mathbf{6 0 0} \\
\mathbf{1 0 0 \%})\end{array}$ \\
\hline Contraceptive history & $230(54.8 \%)$ \\
\hline Ever used & $175(41.5 \%)$ \\
\hline Never used & $15(3.7 \%)$ \\
\hline Not applicable & $80(18.9 \%)$ \\
\hline Gynecological morbidity & $340(81.1 \%)$ \\
\hline $\begin{array}{l}\text { Ever diagnosed as having a } \\
\text { gynecological morbidity }\end{array}$ & $3(0.7 \%)$ \\
\hline $\begin{array}{l}\text { Did not have a diagnosis of } \\
\text { gynecological morbidity }\end{array}$ & $2(0.5 \%)$ \\
\hline Gynecological cancers & $1(0.2 \%)$ \\
\hline Breast cancer & $163(38.8 \%)$ \\
\hline Ovarian cancer & $112(26.7 \%)$ \\
\hline Cervical cancer & $147(35.0 \%)$ \\
\hline Other chronic conditions and risk factors \\
\hline High blood pressure & $61(14.5 \%)$ \\
\hline Type 2 DM & $189(46.4 \%)$ \\
\hline High cholesterol & \\
\hline Other medical conditions & \\
\hline $\begin{array}{l}\text { Waist circumference }>80 \mathrm{~cm} / \text { central } \\
\text { obesity (N=600) }\end{array}$ & \\
\hline
\end{tabular}

Table 3: Prevalence of menopause related symptoms by domains of the green climacteric scale.

\begin{tabular}{|llllll|}
\hline GCS domain & Mild $\mathbf{n}(\boldsymbol{\%})$ & $\begin{array}{l}\text { Moderate } \mathbf{n} \\
(\boldsymbol{\%})\end{array}$ & $\begin{array}{l}\text { Severe } \\
\mathbf{n}(\boldsymbol{\%})\end{array}$ & $\begin{array}{l}\text { Total } \\
(\mathbf{1 0 0} \%)\end{array}$ & $\begin{array}{l}\text { Prevalence }(\boldsymbol{\%}) \\
\mathbf{9 5} \% \text { with }\end{array}$ \\
\hline GCS total & $\mathbf{5 2 ( 1 2 . 4 \% )}$ & $\mathbf{1 0 6}(25.2 \%)$ & $245(58.3 \%)$ & 420 & $95.95(93.73-97.54)$ \\
\hline Psychological symptoms & $31(7.4 \%)$ & $96(22.9 \%)$ & $238(56.7 \%)$ & 420 & $86.90(83.42-89.88)$ \\
\hline Physical symptoms & $7(1.7 \%)$ & $49(11.7 \%)$ & $296(70.5 \%)$ & 420 & $89.28(86.05-91.98)$ \\
\hline Vasomotor symptoms & $5(1.2 \%)$ & $23(5.5 \%)$ & $207(49.3 \%)$ & 420 & $55.95(51.17-60.65)$ \\
\hline Sexual dysfunction score & $79(26.9 \%)$ & $84(28.6 \%)$ & $30(10.2 \%)$ & $294 *$ & $65.64(60.08-70.91)$ \\
\hline
\end{tabular}

*Not applicable/refused to answer/missing value omitted from the analysis.

In Table 3 menopause related symptoms were assessed using the green climacteric scale (GCS) which has four domains such as psychological symptoms, physical or somatic symptoms, vasomotor symptoms, and sexual dysfunction. There were 21 questions distributed among the four domains of the scale with an option of 4 potential responses, not at all, mild, moderate to severe. Among 420 participants $56.7 \%$ of the women had severe psychological symptoms, $70.5 \%$ has severe physical symptoms, and $49.3 \%$ has severe vasomotor symptoms. Among those who could report on their menopause symptoms (294 women), 28.6\% had moderate sexual dysfunction. On the whole, $58.3 \%$ of the women were severely affected by menopause-related symptoms.

In Table 4 severity of menopause-related symptoms by the specific menopausal stage and domains of the GCS were assessed nearly two-thirds of the women $(65.3 \%)$ in the postmenopausal stage were having severe psychological symptoms. There was no variation in physical or vasomotor symptoms among three menopausal stages. There was a sharp increase in the 
percentage of women reporting severe sexual dysfunction symptoms from those in menopause transition to early and late menopause stages from 3.5 to $11.4 \%$ and $13.7 \%$ respectively.

Table 4: Severity of menopause related symptoms by menopause status and domains of the green climacteric scale.

\begin{tabular}{|llllll|}
\hline GCS domain & Severity & $\begin{array}{l}\text { Menopause } \\
\text { transition }\end{array}$ & $\begin{array}{l}\text { Early post } \\
\text { menopause }\end{array}$ & $\begin{array}{l}\text { Late post } \\
\text { menopause }\end{array}$ & $\begin{array}{l}\text { Chi-square } \\
\text { p value }\end{array}$ \\
\hline Psychological severe & & $49(47.6 \%)$ & $46(46.9 \%)$ & $143(65.3 \%)$ & 0.001 \\
\hline Total (\%) & & $103(100 \%)$ & $98(100 \%)$ & $219(100 \%)$ & $420(100 \%)$ \\
\hline Physical severe & Severe & $76(73.8 \%)$ & $65(66.3 \%)$ & $155(70.8 \%)$ & 0.506 \\
\hline Total (\%) & & $103(100 \%)$ & $98(100 \%)$ & $219(100 \%)$ & $420(100 \%)$ \\
\hline Vasomotor severe & Severe & $55(53.4 \%)$ & $53(54.1 \%)$ & $99(45.2 \%)$ & 0.217 \\
\hline Total (\%) & & $103(100 \%)$ & $98(100 \%)$ & $219(100 \%)$ & $420(100 \%)$ \\
\hline Sexual dysfunction & Severe & $3(3.5 \%)$ & $8(11.4 \%)$ & $19(13.7 \%)$ & $0.048 *$ \\
\hline Total (\%) & & $85(100 \%)$ & $70(100 \%)$ & $139(100 \%)$ & $294(100 \%)$ \\
\hline
\end{tabular}

*One cell value is less than 5 .

Table 5: Menopause related symptoms-average scores using green climacteric scale.

\begin{tabular}{|llll|}
\hline Domain & Average score mean (SD) & Observed range & Expected range \\
\hline Psychological-anxiety & $6.67(4.92)$ & $0-18$ & $0-18$ \\
\hline Psychological-depression & $4.56(3.51)$ & $0-14$ & $0-15$ \\
\hline Physical symptoms & $7.61(4.86)$ & $0-21$ & $0-21$ \\
\hline Vasomotor symptoms & $2.74(2.66)$ & $0-6$ & $0-6$ \\
\hline Sexual dysfunctional score & $1.14(1.01)$ & $0-3$ & $0-3$ \\
\hline Total score-GCS & $22.39(11.90)$ & $0-52$ & $0-63$ \\
\hline
\end{tabular}

Table 6: Distribution of women with menopause related symptoms and lifestyle factors, reproductive health history, other medical history.

\begin{tabular}{|c|c|c|c|c|c|}
\hline \multirow[t]{2}{*}{$\begin{array}{l}\text { Independent } \\
\text { variable }\end{array}$} & \multirow[t]{2}{*}{ Category } & \multicolumn{2}{|c|}{ Menopause related symptoms } & \multirow[t]{2}{*}{$\begin{array}{l}\text { Total N } \\
(100 \%)\end{array}$} & \multirow[t]{2}{*}{$\begin{array}{l}\text { Chi-square } \\
\text { p-value }\end{array}$} \\
\hline & & Severe & Not severe & & \\
\hline \multirow{2}{*}{$\begin{array}{l}\text { Complication during } \\
\text { delivery }\end{array}$} & Yes & $23(60.5 \%)$ & $15(39.5 \%)$ & $38(100 \%)$ & 0.862 \\
\hline & No & $215(59.1 \%)$ & $149(40.9 \%)$ & $364(100 \%)$ & \\
\hline \multirow{2}{*}{$\begin{array}{l}\text { Gynecological } \\
\text { morbidity }\end{array}$} & Ever had & $59(73.8 \%)$ & $21(26.3 \%)$ & $80(100 \%)$ & 0.002 \\
\hline & Never had & $186(54.7 \%)$ & $154(45.3 \%)$ & $340(100 \%)$ & \\
\hline \multirow{2}{*}{$\begin{array}{l}\text { Gynecological } \\
\text { surgery }\end{array}$} & Underwent & $48(70.6 \%)$ & $20(29.4 \%)$ & $68(100 \%)$ & $\mathrm{NA}^{*}$ \\
\hline & Never underwent & $10(83.3 \%)$ & $2(16.7 \%)$ & $12(100 \%)$ & \\
\hline \multicolumn{6}{|c|}{ Other health condition and menopause-related symptoms } \\
\hline \multirow{2}{*}{ High blood pressure } & Yes & $105(64.4 \%)$ & $58(35.6 \%)$ & $163(100 \%)$ & 0.044 \\
\hline & No & $140(54.5 \%)$ & $117(45.5 \%)$ & $257(100 \%)$ & \\
\hline \multirow{2}{*}{ Diabetes mellitus } & Yes & $68(60.7 \%)$ & $44(39.3 \%)$ & $112(100 \%)$ & 0.551 \\
\hline & No & $177(57.5 \%)$ & $131(42.5 \%)$ & $308(100 \%)$ & \\
\hline \multirow{2}{*}{ High cholesterol } & Yes & $99(67.3 \%)$ & $48(32.7 \%)$ & $147(100 \%)$ & 0.006 \\
\hline & No & $146(53.5 \%)$ & $127(46.5 \%)$ & $273(100 \%)$ & \\
\hline \multirow{2}{*}{$\begin{array}{l}\text { Other medical } \\
\text { conditions }\end{array}$} & Yes & $46(75.4 \%)$ & $15(24.6 \%)$ & $61(100 \%)$ & 0.003 \\
\hline & No & $199(55.4 \%)$ & $160(44.6 \%)$ & $359(100 \%)$ & \\
\hline \multirow[t]{2}{*}{ Central obesity } & Waist circumference $<80 \mathrm{~cm}$ & $124(56.9 \%)$ & $94(43.1 \%)$ & $218(100 \%)$ & 0.530 \\
\hline & Waist circumference $>80 \mathrm{~cm}$ & $121(59.9 \%)$ & $81(40.1 \%)$ & $202(100 \%)$ & \\
\hline
\end{tabular}

Table 5, shows the GCS scale scores by domain were computed and this has been tabulated along with the observed and expected ranges in table 4.7. The average score for the psychological anxiety subscale and depression subscale was 6.67 with a standard deviation of 4.9 and 46 with a standard deviation of 3.5 respectively. The average score for physical symptoms was 7.61 with a standard deviation of 4.86. The average score for vasomotor symptoms is 2.7 with a standard deviation of 
2.7. The mean score for sexual dysfunction was 1.1 with a standard deviation of 1.0. The domains of distress concerning menopause-related symptoms seem to be related to psychological-anxiety related and also physical symptoms.

Table 6, pattern of health care seeking by the women who experienced menopause-related symptoms has been examined by categorizing care-seeking into those who sought care at least once sought care for any symptoms and those who never sought care for any symptoms. This enabled the identification of key factors associated with health care seeking for MRS.

\section{DISCUSSION}

The common severe psychological symptoms were psychological anxiety with subdomains of the heart beating quickly or strongly $(61.1 \%)$ and difficulties in sleeping $(55.95 \%)$. The psychological symptom which was the most frequent was feeling tired or lacking energy $(68.09 \%)$ and it was severe for $48.3 \%$ of the women and the most common mild psychological symptom was crying spells $(65.4 \%)$ and it was present in $37.1 \%$ of women. Physical symptoms were assessed using a sevensymptom scale and the most frequently reported physical symptom was muscle and joint pain $(73.3 \%)$ and 62 percent of women have severe muscle and joint pain. ${ }^{10}$ Vasomotor symptoms were hot flushes and night sweats. Hot flush was present in $54.5 \%$ of the women and it was severe for $62 \%$ of those with such symptoms. Night sweats were present in $55.2 \%$ of the women and it was severe in $61.2 \%$ of them. ${ }^{11}$ The study findings were muscle and joint pain $95 \%(\mathrm{p}<0.0001)$, parts of the body feeling numb or tingling $93.3 \%(\mathrm{p}<0.0001)$, difficulty in sleeping $86.5 \%(p<0.0001)$, irritability $85.8 \%(p<0.0001)$ and these rates were significantly higher than those reported in the current study, but the prevalence of muscle and joint pain $(\mathrm{p}<0.14)$ were similar to the study findings vasomotor symptoms like hot flushes $46.7 \%$ $(\mathrm{p}<0.0013)$ and night sweats 50\% $(\mathrm{p}<0.032)$ reported from the study based. ${ }^{12,13}$ The study findings concur with Global and Asian study findings regarding more prevailing symptoms as physical than vasomotor symptoms Kulkarni et al women in late menopause, who had induced menopause and premature menopause was affected by severe symptoms. There was a significant positive correlation between postmenopausal symptoms and age. ${ }^{14}$ The participants who reported having ever been diagnosed with gynecological morbidity, high blood pressure, high cholesterol, and other medical conditions are more likely to have severe symptoms. ${ }^{15}$ The present study findings of correlates of menopause-related symptom severity are in correspondence with existing knowledge in terms of low economic status, less family support, and presence of chronic diseases. Multivariate analysis indicated that family support is a significant correlate of the severity of menopause-related symptoms after controlling for other factors. ${ }^{16}$

\section{CONCLUSION}

The factors associated with the severity of menopauserelated symptoms are a type of menopause, age at menopause, education, economic status, and family support. Family support tends to mitigate against severe symptoms. The study participants sought care mainly for physical symptoms rather than any other menopauserelated symptoms. They did not seek care for sexual dysfunction even though many women reported these symptoms. Health seeking behaviour was not associated with the nature of menopause or any of the sociodemographic or economic factors; but it was associated with the history of previous menstrual history, gynecological morbidity, type 2 diabetes mellitus and other medical conditions. This indicates a lack of knowledge regarding treatable menopause-related symptoms.

\section{Funding: No funding sources}

Conflict of interest: None declared

Ethical approval: The study was approved by the Institutional Ethics Committee

\section{REFERENCES}

1. Broker SA, Venugopalan PP, Bhat SN. Study of menopausal symptoms, and perceptions about menopause among women at a rural community in Kerala. J Midlife Health. 2013;4:182-7.

2. Gandhi AB, Shukla AKR. Evaluation of BMD of women above 40 years of age. J Obstet Gynecol India. 2005;55(3):265-7.

3. Geukes M, van Aalst MP, Nauta MC, Oosterhof H. The impact of menopausal symptoms on workability: menopause. The J North Am Menopause Society. 2012;19(3):278-82.

4. Greene JG. Constructing a standard climacteric scale. Maturitas. 1998;29(1):25-8.

5. Grigoriou V, Augoulea A, Armeni E, Rizos D, Alexandrou A, Dendrinos S, et al. Prevalence of vasomotor, psychological, psychosomatic and sexual symptoms in perimenopausal and recently postmenopausal Greek women: association with demographic, life-style and hormonal factors. Gynecol Endocrinol. 2013;29(2):125-8.

6. Hilditch JR, Lewis J, Peter A, van Maris B, Ross A, Franssen E, et al. A menopause-specific quality of life questionnaire: development and psychometric properties. Maturitas. 1996;24:161-75.

7. Ishizuka B, Kudo Y, Tango T. Cross-sectional community survey of menopause symptoms among Japanese women. Maturitas. 2001;61(3):260-7.

8. Janssen I. Menopause and the metabolic syndrome. The study of women's health across the Nation. Arch Internal Med. 2008;168(14):1568.

9. Jaspers L, Daan NM, Van Dijk GM, Gazibara T, Muka T, et al. Health in middle-aged and elderly women: a conceptual framework for healthy menopause. Maturitas. 2015;81(1):93-8. 
10. Kakkar V, Kaur D, Chopra K, Kaur A, Kaur IP. Assessment of the variation in menopausal symptoms with age, education and working/nonworking status in north-Indian sub population using menopause rating scale (MRS). Maturitas. 2007;57(3):306-14.

11. Kaufert PA. The social and cultural context of menopause. Maturitas. 1996;23(2):169-80.

12. Kaulagekar A. Age of menopause and menopausal symptoms among urban women in Pune, Maharashtra. J Obstet Gynecol India. 2011;61:323-6.

13. Khan S, Shukla MK, Priya N, Ansari MA. Health seeking behaviour among post-menopausal women: a knowledge, attitude and practices study. Inter $\mathbf{J}$ Comm Med Pub Health. 2016;3(7):1777.

14. Kulkarni P, Rani BS, Kumar DS, Manjunath R. Burgeoning menopausal symptoms: An urgent public health concern. J Mid-life Health. 2016;7(2):83.
15. Mishra S. Menopausal transition and postmenopausal health problems: a review on its biocultural perspectives. Health. 2011;3(4):233-7.

16. Lejsková M, Alušík Š, Suchánek M, ŽŽecová S, Pit'tha J. Menopause: clustering of metabolic syndrome components and population changes in insulin resistance. Climacteric. 2011;14(1):83-91.

Cite this article as: Shwetha S, Minnalkodi SNS, Prasad G. Prevalence of gynecological diseases in postmenopausal women in tertiary care hospital in Chengalpattu district. Int J Reprod Contracept Obstet Gynecol 2020;9:3590-5. 